\title{
0 papel das redes de transformação no processo de inovação: estudos de caso sobre a descoberta e a comercialização da inovação
}

\author{
Marinez Cristina Vitorelia*, Jose Alcides Gobbo Junior ${ }^{\mathrm{b}}$ \\ a*marinez.adm@hotmail.com, UNESP, Brasil \\ bgobbo@feb.unesp.br, UNESP, Brasil
}

\begin{abstract}
Resumo
A importância da inovação é algo reconhecido. Nesse contexto, as redes de inovação ganham importância nos estudos acadêmicos, uma vez que uma organização, isoladamente, nem sempre tem acesso a todos os recursos necessários. Gobbo Junior e Olsson (2010) apresentam um modelo de inovação em rede segundo o qual as redes de transformação seriam as estruturas presentes entre as de exploração e aplicação. Nesse contexto, este artigo apresenta dois estudos de caso de inovação em redes, tendo como objetivo aumentar a compreensão sobre as redes de transformação. Busca-se entender como elas interligam as redes de exploração e aplicação, os principais atores presentes nessa interface e avaliar se esses atores podem atuar como agentes aceleradores do processo de inovação. Foi possível verificar como as redes de transformação interligam as redes de exploração e aplicação, bem como identificar suas práticas e principais atores.
\end{abstract}

Palavras-chave

lnovação. Teoria de redes. Redes de exploração e aplicação. Modelos de inovação em rede.

\section{Introdução}

A importância da inovação é reconhecida. Almejada pelas empresas, sua prática passou a ser um grande desafio, pois a própria literatura sobre 0 assunto (AHUJA, 2000; CHESBROUGH; GARMAN, 2009; HARRYSON; DUDKOWSKI; STERN, 2008) aponta as dificuldades em se estabelecer práticas que possam auxiliar esse processo. Neste contexto, as redes de inovação ganham importância nos estudos acadêmicos, uma vez que uma organização, isoladamente, nem sempre tem acesso a todos os recursos necessários, além da difícil escolha entre focar em suas competências principais ou diversificar, explorando novas oportunidades de mercado.

As redes definem novos arranjos organizacionais, adaptáveis e flexíveis (KALLINIKOS, 2004). Segundo Cândido e Abreu (2000), a aplicação das redes organizacionais no ambiente empresarial advém do aumento da competitividade e do entendimento de que ações isoladas das organizações inviabilizam sua sobrevivência e desenvolvimento. Dessa forma, acredita-se ser mais provável que a inovação aconteça em alguma forma de rede. Nesse contexto, os elos estratégicos das redes têm recebido maior investimento em inovação (PIRES; SACOMANO NETO, 2010).

A literatura (MARCH, 1991; BENNER; TUSHMAN, 2003; GRANT; BADEN-FULLER, 2004; GILSING; DUYSTERS, 2008; HARRYSON; DUDKOWSKI; STERN, 2008) identifica dois tipos principais de redes - exploração e aplicação. Exploração inclui busca, descoberta e experimentação para a geração de novos conhecimentos, enquanto aplicação diz respeito à seleção, aperfeiçoamento, utilização e aplicação dos conhecimentos existentes. Ambas as redes são complementares e necessárias para a criação e captura de valor, porém pouco se sabe sobre como é estabelecida a ligação entre elas. 
Harryson, Dudkowski e Stern (2008) apresentam um modelo de inovação em rede, segundo o qual as redes de transformação seriam as estruturas presentes entre as de exploração e aplicação. Num desdobramento dessa proposição, Gobbo Junior e Olsson (2010) apresentam um modelo de processo de inovação em rede semelhante, porém com dois tipos de análise: 1) no nível das redes; e 2) no nível de desenvolvimento do produto, indicando que a inovação ocorre em sentido horário ao do modelo proposto, identificando os possíveis atores presentes entre as redes de exploração e aplicação.

Nesse contexto, este artigo apresenta dois estudos de caso de inovação em redes, tendo como objetivo aumentar a compreensão sobre as redes de transformação. Busca-se entender como elas interligam as redes de exploração e aplicação, os principais atores presentes nessa interface e avaliar se esses atores podem atuar como agentes aceleradores do processo de inovação. Optou-se por analisar os estudos de caso apresentados conforme o modelo de inovação proposto por Gobbo Junior e Olsson (2010), uma vez que esses autores aprofundaram seus estudos sobre as redes de transformação e identificaram os possíveis tipos de ator presentes nessa interface.

A principal justificativa da presente pesquisa é a necessidade de: (a) ampliar os conhecimentos acerca das redes de transformação; (b) identificar os principais tipos de ator presentes nesse tipo de rede; (c) compreender melhor o papel desempenhado pelas redes de exploração, aplicação e transformação. Foram levantadas as seguintes questões de pesquisa: Como as redes de transformação interligam as redes de exploração e aplicação? Quais os principais tipos de ator nelas presentes? Seriam as redes de transformação agentes aceleradores do processo de inovação?

\section{Revisão teórica}

Segundo Freeman (1982), a inovação é uma ideia ou modelo com o qual se pode melhorar um produto, equipamento, processo ou sistema. Já Schumpeter (1955) define inovação como a "descoberta" de algo novo ou de uma nova maneira de fazer algo. Numa versão mais atual, Christensen, Olesen e Kjaer (2005) diferenciam inovação de invenção, afirmando que, para se tornar uma inovação, é necessário que a invenção altere o equilíbrio existente (status quo) bem como gere algum benefício econômico.

Gobbo Junior e Vasconcellos (2008) apresentam algumas características relativas à inovação: (1) Novidade: deve ser algo novo para a organização, para o ramo de negócios, para a comunidade ou para o mercado como um todo, (2) Concretude: deve, necessariamente, ter sido colocada em prática, e (3) Utilidade: deve ter melhorado o valor percebido pelo cliente quando interage com a empresa.

Henry Chesbrough foi o primeiro autor a usar o termo "inovação aberta", afirmando que as empresas podem e devem utilizar ideias tanto internas como externas em suas atividades de inovação. Vários autores (POWEL; KOPUT; SMITH-DOER, 1996; UZZI, 1997; NOOTEBOOM, 1992; 1999; 2004; AHUJA, 2000; ROWLEY; BERENS; KRACKHARDT, 2000, CALIA; GUERRINI; MOURA, 2007; COWAN; JONARD; ZIMMERMANN, 2007) indicam uma tendência de as organizações buscarem parcerias que possam auxiliá-las na prática de inovação. Segundo Calia, Guerrini e Moura (2007), as redes de inovação são um efeito lógico da crescente complexidade de produtos e serviços inovadores e representam uma solução organizacional para esse problema (PYKA; KUPPERS, 2002 apud CALIA; GUERRINI; MOURA, 2007).

Nesse contexto, os modelos e processos tradicionais de inovação experimentam uma evolução linear, partindo de um sistema tradicional fechado para um mais aberto e estratégico (BERTHON; HULBERT; PITT, 1999; CHESBROUGH, 2003; EASTERBY-SMITH; CROSSAN; NICOLINI, 2000; PISANO, 1990; 1991; SAWHNEY, 2002; SHENKAR; LI, 1999; TEECE, 1986). Amato Neto (2005) destaca a importância da formação de redes como uma solução alternativa viável, principalmente para as pequenas e médias empresas (PMEs), que geralmente se encontram em desvantagem nas atividades de inovação frente às grandes corporações.

Para uma melhor compreensão das redes organizacionais, é necessário conhecer sua estrutura. Segundo Wasserman e Faust (1994), são elementos dessa estrutura: centralidade - um ator centraliza a relação com os outros atores, obtendo vantagens; equivalência estrutural - os atores ocupam posições semelhantes; densidade - os atores possuem fortes ligações uns com os outros; e coesão - um ou alguns atores exercem o domínio sobre a rede.

Segundo Britto (2002), quatro elementos morfológicos constituem a estrutura das redes: nós (empresas que fazem parte da configuração da rede); posições (divisão do trabalho); ligações (tipos de relacionamentos existentes) e fluxos (bens e informações que circulam na rede).

Quanto à análise das redes, existem aspectos estruturais e relacionais, que contribuem grandemente para o conceito embeddedness, termo criado por Granovetter (1973) que significa "grau de imersão", e trata sobre quão imerso pode estar um indivíduo e/ou empresa e/ou grupo social em uma sociedade que molda seus pensamentos, valores, crenças e 
atitudes. As redes também podem ser classificadas como densas ou difusas, e quanto maior for a interconexão, maior será a densidade. Redes fechadas, geralmente, são compostas por laços fortes e densos entre os atores, enquanto nas redes difusas, o grau de interconexão é relativamente menor. A rede aberta trata, principalmente, da transferência de recursos e de informações e é composta por laços fracos e esparsos entre seus atores, enquanto a rede fechada centra-se no intercâmbio social, na confiança e em normas partilhadas. Os laços que conectam seus atores são fortes e densos (GRANOVETTER, 1973; COLEMAN, 1988; BURT, 1992).

Harrison e Carroll (2002) fazem uma distinção entre redes com dois focos: extra e intracorporativos. A rede extracorporativa é caracterizada pela criatividade, com laços fracos entre os parceiros, com fontes primárias de especialização do conhecimento e tecnologias centradas na aplicação da inovação por meio da colaboração. Já as redes intracorporativas caracterizam-se por laços fortes em suas parcerias com foco na exploração da inovação. Complementarmente, Benner e Tushman (2003) definem as redes de exploração como aquelas que têm foco na busca, descoberta e experimentação para a geração de novos conhecimentos, enquanto as de aplicação são caracterizadas pela seleção, aperfeiçoamento e utilização dos conhecimentos existentes.

Harryson, Dudkowski e Stern (2008) apresentam um tipo de rede intermediária, a qual denominaram "rede de transformação", a qual seria a responsável por fazer a interligação entre as redes de exploração e as de aplicação, complementado o processo de inovação em redes. Segundo March (1991), tanto a exploração quanto a aplicação são necessárias à sobrevivência do sistema, apesar das incertezas da exploração e da dificuldade de se fazer as duas ao mesmo tempo, o que leva a maioria das organizações a centrar-se na aplicação.

Evidências confirmam (AHUJA, 2000; CALIA; GUERRINI; MOURA, 2007; GUPTA; SMITH; SHALLEY, 2006) que os laços fracos são suscetíveis de acelerar a velocidade de desenvolvimento em fases iniciais de exploração, quando o conhecimento requerido não é complexo, porém podem diminuir a velocidade em situações de alta complexidade do conhecimento, quando os laços fortes são necessários para sustentar a aplicação da inovação. Assim, a comercialização de inovações radicais requer a gestão dupla dos laços fortes e fracos.

Gobbo Junior e Olsson (2010) apresentaram um modelo de inovação em rede semelhante ao proposto por Harryson, Dudkowski e Stern (2008), porém com uma lógica interna diferente e complementando-o com os conceitos da teoria C-K, conforme ilustrado na Figura 1. Segundo o argumento dos autores, a implementação de inovação radical requer a transferência e transformação de recursos em inovação por meio de múltiplos tipos de redes. As redes de transformação, que partem de uma rede de aplicação para uma de exploração, são constituídas por arranjos colaborativos organizacionais com foco na busca e experimentação do conhecimento e recursos complementares, tendo como atores típicos empreendedores, universidades, agências governamentais e provedores de soluções tecnológicas. Em contrapartida, os principais atores que fazem a intersecção entre as redes de exploração e as redes de aplicação são agências financiadoras, capitalistas de risco e empreendedores, que proporcionam os

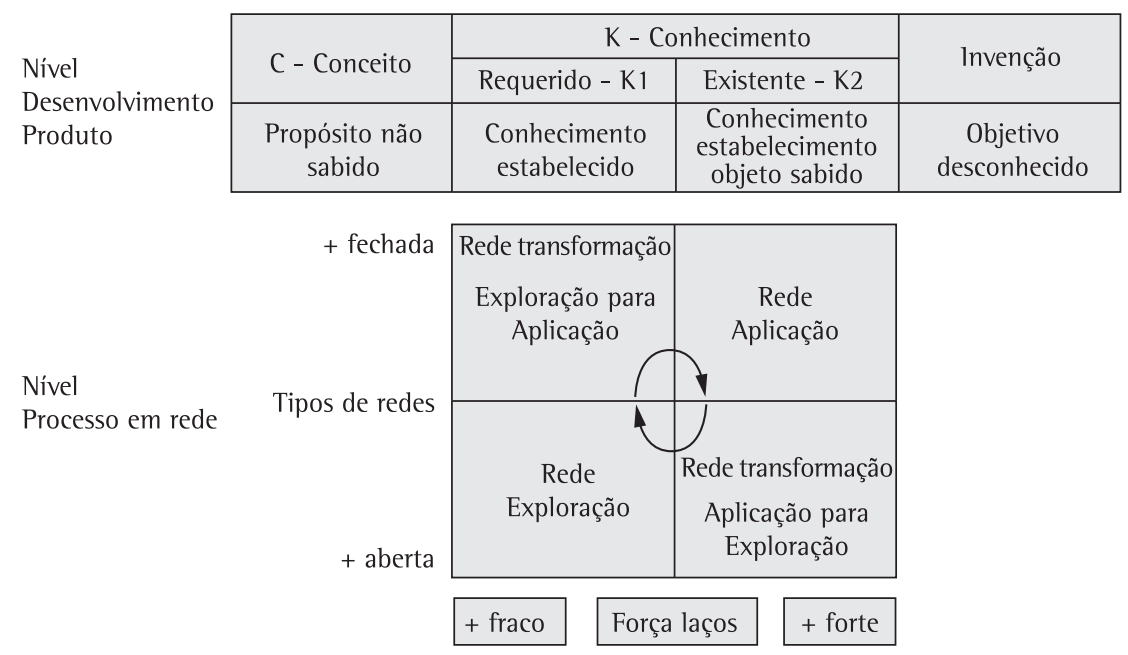

Figura 1. Modelo de Inovação em Rede (GOBBO JUNIOR; OLSSON, 2010). 
recursos necessários à empresa para que ela possa levar seus conhecimentos ao mercado, transformando ideias em inovações.

Para entender o modo como essas atividades relacionam a formulação de um conceito/ideia com a busca de conhecimento, ao longo dos diferentes tipos de rede, os autores integram a teoria de redes com o desenvolvimento da inovação. A Teoria C-K serve como um complemento para a teoria de redes, adicionando o nível de design do produto ao esquema teórico. Neste esquema teórico, os autores realizam dois tipos de análise: no nível do desenvolvimento de produto e no nível do processo em rede.

No nível do desenvolvimento do produto, utilizam os princípios da teoria C-K onde C (concept) é o conceito, existente ou não, e K (knowledge) é o conhecimento, que, no caso, é divido em conhecimento existente (dentro das fronteiras da rede focal - K1) e conhecimento requerido (fora das fronteiras da rede focal - K2). Esta proposição de teoria foi originalmente escrita por Hatchuel e Weil (2003), que partem do pressuposto de que o design do produto pode ser modelado pela interação entre conceitos e conhecimentos. $\mathrm{O}$ espaço $\mathrm{K}$ contém todas as proposições estabelecidas (verdadeiras) que representam o conhecimento disponível. Mas K também é expansível dado que um novo conhecimento é desenvolvido em relação ao conceito (C). 0 espaç̧o C também é expansível e contém conceitos cujos propósitos são parcialmente desconhecidos sobre os objetos X. O ponto de partida de um projeto de design é descrito em termos pragmáticos como uma "ideia" ou "especificações resumidas". Essas expressões tentam descrever um objeto que não é completamente definido e cuja condição de existência não é completamente conhecida.

No segundo nível de análise - do processo em rede - os autores afirmam que o empreendedor pode sair de uma rede do tipo exploração para uma rede de aplicação e vice-versa, identificando os principais tipos de ator que fazem a ligação entre elas. 0 conhecimento existente do empreendedor pode ser relacionado à rede na qual o ator está inserido. 0 empreendedor move-se ao longo das redes no sentido horário, buscando nos espaços K1 e K2 a solução de um dado problema ou "ideia".

\section{Método de pesquisa}

A estratégia de pesquisa selecionada foi o estudo de caso, por se mostrar uma opção adequada, procurando aprofundar o conhecimento da realidade ao dar explicações para fenômenos pouco explorados (YIN, 2005). Trata-se de um estudo de natureza exploratória, porque busca compreender um fenômeno da atualidade.

As redes de exploração, de utilização e de transformação foram analisadas sob dois aspectos: (a) Estrutura da rede (aberta ou fechada); e (b) Força do laço. Para análise das redes de transformação, foi utilizada a abordagem nominalista proposta por Knoke e Kuklinski (1982) segundo a qual as redes abertas e fechadas são diferenciadas considerando-se somente os aspectos relevantes da rede e a força de laços. Foi considerada rede aberta aquela cujo foco é, principalmente, proporcionar a troca de recursos de informação, e rede fechada aquela cujo foco é, principalmente, a confiança entre seus membros, normas partilhadas e trocas sociais.

A análise das forças de laço foi feita conforme as proposições de Granovetter (1973). As dimensões propostas originalmente pelo autor são muito amplas para um estudo de inovação, então decidiu-se adaptar e usar somente três dessas dimensões: frequência de interação, quantidade de tempo e escopo de conteúdo.

- Frequência de interação indicará a extensão desse relacionamento no tempo, diferenciada mediante os termos frequência alta, média e baixa, sendo considerada alta quando, num período de 1-2 anos, a parceria for mantida durante todo o tempo; média, quando ao longo desse mesmo período, o parceiro for acessado apenas para tratar de assuntos específicos; e baixa quando o parceiro, ocasionalmente, for acessado apenas como um suporte;

- Quantidade de tempo considerará a extensão de uma relação no tempo, diferenciada em curta, média e longa. A quantidade de tempo foi considerada longa quando, num período de 1-2 anos, a parceria for mantida ao longo de todo esse tempo; média quando, ao longo desse mesmo período, a parceria for mantida apenas até um determinado ponto; curta quando for acessada apenas para algumas atividades específicas e após dispensada ou, simplesmente, não mantida; e

- A análise no escopo do conteúdo indicará a extensão e profundidade do conhecimento partilhado e, também, os diferentes conteúdos de conhecimento, sendo ele classificado em limitado, mediano ou extenso, considerando as questões tecnológicas e não tecnológicas. Esse dado revelará o quanto de conhecimento flui de uma rede para a outra, podendo indicar, inclusive, o grau de confiança que existe nessa relação. 0 escopo de conteúdo foi considerado extenso quando, num período de tempo (1-2 anos), vários tipos de conhecimento (tecnológico, mercado, entre outros) fluem livremente entre um parceiro e outro, podendo ser acessados a qualquer momento. Será considerado mediano quando, ao longo desse mesmo período de tempo, mais de um tipo de conhecimento fluir; e será considerado 
limitado quando, nesse mesmo período de tempo, apenas um tipo de conhecimento fluir. 0 Quadro 1 ilustra essa proposição.

A presente pesquisa apresenta dois estudos de inovação, em duas empresas do setor químico localizadas no interior do estado de São Paulo. Optou-se por analisar os estudos de caso segundo o modelo de inovação em rede proposto por Gobbo Junior e Olsson (2010), uma vez que os autores foram pioneiros na identificação dos tipos de ator presentes nas redes de transformação. Adicionalmente, buscou-se reforçar ou refutar a proposição dos autores.

0 histórico das empresas e as estratégias adotadas por elas foram levantados por meio de publicações em revistas especializadas e a coleta de dados foi feita por meio de entrevistas semiestruturadas, com pessoas diretamente envolvidas no processo de inovação das empresas. A validação do constructo se deu a partir do modelo proposto por Knoke e Kuklinski (1982). A partir da análise da frequência de interação, quantidade de tempo e escopo do conteúdo, foi possivel mapear o caminho que a inovação percorreu, bem como compreender como as redes de transformação interligam as redes de exploração e aplicação.

\subsection{Estudo de caso da empresa $A$}

A empresa chamada foi fundada no ano de 2004, por três estudantes de química, iniciando suas atividades no laboratório da faculdade. Localizada no interior do estado de São Paulo, desenvolve soluções antibacterianas utilizando conceitos da nanotecnologia. Os três estudantes eram bolsistas de agências de fomento à pesquisa e, portanto, tinham acesso a diversos projetos nos quais era possível identificar várias oportunidades de mercado com o uso dos princípios da nanotecnologia. Para facilitar a compreensão da inovação gerada pela empresa $\mathrm{A}$, o período total foi dividido em três fases: a) período da pré-ideia (2004-2005), b) viabilização da ideia (2006-2008), e c) comercialização da ideia (2009-2010).

No período da pré-ideia (de 2004 a 2005), os três estudantes (empresários) ainda não sabiam qual seria o produto final da empresa. Desejavam utilizar os princípios da nanotecnologia em outros tipos de materiais e não somente o metal, como vinha sendo feito. Nesse momento, as parcerias estabelecidas foram com o laboratório da Universidade, a Fundação de Amparo à Pesquisa do Estado São Paulo - FAPESP e o Serviço de Apoio Brasileiro às Micro e Pequenas Empresas - SEBRAE. A FAPESP, por meio do programa de Pesquisa Inovativa em Pequenas Empresas (PIPE), financiou $100 \%$ das pesquisas iniciais. 0 laboratório foi a sede da empresa, nesse período, e nele foram feitas as pesquisas para o desenvolvimento da tecnologia. O SEBRAE, por intermédio do programa Sebraetec, que consiste numa assessoria empresarial inicial, forneceu os primeiros subsídios mercadológicos, como pesquisas de mercado, desenho de logomarca e layout do cartão de visitas.

No período de viabilização da ideia (2006 a 2008), houve a entrada de um novo parceiro, um fundo de investimentos que aportou uma quantidade de capital em troca de participação na empresa, alterando sua natureza social para Sociedade Anônima. Nesse período, foi fechado um contrato com seu primeiro cliente e contratados, por indicação do fundo de investimento, serviços de consultoria e coaching cujo objetivo era assessorar empresas de base tecnológica na solução de problemas decorrentes da expansão dos seus negócios e na preparação para a entrada de recursos de terceiros, dando direito de participação acionária desses junto à empresa A. Nessa fase, as parcerias desenvolvidas foram: laboratório da faculdade, onde ainda realizavam-se algumas pesquisas, FAPESP, SEBRAE, o fundo de investimento e a empresa de consultoria.

No período da comercialização da ideia (2009-2010), foi fechado contrato com um grande grupo estrangeiro fabricante de eletrodomésticos, que aplica a tecnologia desenvolvida em sua linha antibacteriana. Atualmente as parcerias estabelecidas são: fundo de investimento, empresa de consultoria (que passaram a ser sócios), laboratório da faculdade e a FAPESP.

\subsection{Estudo de caso empresa $B$}

A empresa chamada B atua no setor químico. Localiza-se no interior do estado de São Paulo, atendendo à indústria farmacêutica e, principalmente,

Quadro 1. Análise das forças dos laços.

\begin{tabular}{ccc}
\hline Item análise & 0 que mede & Classificação \\
\hline Frequência de interação & Extensão do relacionamento & Alta / Média / Baixa \\
Quantidade de tempo & Curta / Média / Longa da parceria entre os atores & Limitado / Mediano / Extenso \\
Escopo do conteúdo & $\begin{array}{c}\text { Extensão e profundidade do conhecimento } \\
\text { compartilhado e diferentes conteúdos de } \\
\text { conhecimento }\end{array}$ & \\
\hline
\end{tabular}


à indústria cosmética, focando no desenvolvimento de ativos biológicos da biodiversidade brasileira.

A presente pesquisa foi realizada no mês de setembro de 2010 com retrospectiva de oito anos, compreendendo o período de 2002 a 2010. Para facilitar o entendimento das etapas que a empresa percorreu no caminho da inovação, a descrição e a análise desse estudo de caso foram divididas em três etapas, sendo: a) período da pré-ideia (2002-2004), b) período da viabilização da ideia (2005-2007), e c) período da comercialização da ideia (2008-2010). Os dados foram coletados por meio de questionário semiestruturado, respondido diretamente pelo coordenador de desenvolvimento de ativos químicos.

No período da pré-ideia (de 2002 à 2004), a empresa comercializava alguns produtos químicos e desejava expandir suas operações para aumentar o volume de suas exportações. Nessa época, a diretora científica já tinha a intenção de estudar as aquaporinas, ou seja, proteínas tubulares que formam canais entre as células.

Em 2004, a diretora científica da empresa B encontrou um livro de autoria de um professor da área fitoterápica da Universidade Estadual Paulista - UNESP de Botucatu, e, após um contato inicial, contratou o docente para prestar serviços à empresa. Após alguns meses de estudo, o docente apontou as ferramentas de dez plantas com alto potencial de ativos biológicos. De posse do conhecimento sobre as características dessas plantas, a empresa B desenhou seus mecanismos de ação e realizou as primeiras pesquisas no laboratório da UNESP de Botucatu. No final de 2004, a diretora científica ingressou no programa de doutorado e pôde formar sua equipe, contratando pesquisadores (mestrandos e doutorandos).

No período da viabilização da ideia (de 2005 a 2007), a empresa submeteu um projeto ao programa da FAPESP Pesquisa Inovativa em Pequenas Empresas (PIPE). Numa primeira fase, foram liberados aproximadamente 150 mil reais para a viabilização das pesquisas iniciais, que duraram 6 meses (prazo fixado pela própria FAPESP). A segunda fase, que teve início em 2007 e duração de dois anos, recebeu um aporte de aproximadamente 500 mil reais, recursos esses que possibilitaram a contratação de pesquisadores, compra de equipamentos para o laboratório e bens de consumo, entre outros.

No período da comercialização da ideia (de 2008 a 2010), as pesquisas resultaram no lançamento do produto Aquasense, no ano de 2008, tanto no mercado nacional quanto no internacional. Em 2009, a empresa $\mathrm{B}$ enviou o último relatório à FAPESP, finalizando a parceria para esse produto.

\subsection{Discussões sobre os estudos de caso das empresas $A$ e $B$}

Analisando o estudo de caso da empresa A, pode-se afirmar que ela partiu de uma rede do tipo exploração, representada pela universidade, onde obteve acesso a vários tipos de informação. No período da pré-ideia, analisando as forças de laços com cada parceiro, pode-se dizer que, com o laboratório, a frequência de interação foi média, indicando um primeiro indício de alteração do tipo de rede, que começou a fechar. Quanto à quantidade de tempo, classifica-se como média, pois a parceria foi firmada para um projeto específico, num prazo determinado, da duração do projeto. 0 escopo do conteúdo classifica-se como mediano, pois alguns conhecimentos fluíam em ambas as direções, indicando, mais uma vez, que a rede estava começando a se fechar.

A FAPESP exerceu papel de agente financiador, proporcionando os recursos necessários à execução das pesquisas. Assim, classifica-se a frequência de interação como baixa, a quantidade de tempo como curta e escopo do conteúdo como limitado, devido ao papel desempenhado por parceira, ou seja, apenas oferecer os recursos necessários à execução das pesquisas, atuando, mais especificamente, no estabelecimento de uma ligação entre a rede de exploração e aplicação. Com o SEBRAE, a frequência de interação foi baixa, quantidade de tempo, curta e escopo de conteúdo, limitado, uma vez que este ator auxiliou apenas no primeiros suportes à gestão da empresa.

No período de viabilização da ideia, percebe-se que a empresa A estava inserida no final de uma rede aberta, já entrando num tipo de rede fechada. Os equipamentos do laboratório da faculdade ainda eram muito utilizados, principalmente nos testes do produto, o que tornava a frequência de interação alta, com longa quantidade de tempo e extenso escopo de conteúdo compartilhado.

A FAPESP continuou sendo um dos agentes financiadores e essa parceria se manteve ao longo de todo o período da viabilização da ideia, sendo, portanto longa a quantidade de tempo, baixa a frequência de interação e limitado o escopo do conteúdo. 0 SEBRAE permaneceu prestando alguns tipos de serviço, assim, classifica-se como baixa a frequência de interação (quantidade mínima de serviços), média a quantidade de tempo, uma vez que essa parceria não foi mantida até o final desse período, e limitado o escopo de conteúdo, devido à restrição dos conhecimentos acessados.

Com o fundo de investimentos, a frequência de interação passou a ser alta, a quantidade de tempo, longa (foi nessa fase que o fundo de investimentos passou a compor o quadro societário da empresa A) e o escopo de conteúdo compartilhado, mediano. A 
empresa A acessava direta e livremente o conhecimento de cada um, embora o seu papel não fosse o de gerar conhecimentos, mas proporcionar recursos financeiros e estabelecer contatos da empresa com outros atores-chave.

A parceria com a empresa de consultoria, nesse primeiro momento, deu-se por intermédio do fundo de investimentos, que apresentou os seus serviços. Dessa forma, classifica-se como média a frequência de interação, longa a quantidade de tempo, pois foi acessado durante todo o período da viabilização da ideia, e mediano o escopo de conteúdo compartilhado, pois, a princípio, realizava um trabalho de consultoria (conhecimentos específicos).

No período de utilização e comercialização da ideia, as parcerias estabelecidas foram: laboratório da faculdade, FAPESP, fundo de investimento e empresa de consultoria. Com o laboratório, a empresa ainda possui relacionamento, mas em outro projeto, ainda em desenvolvimento, no ramo de etanol, bioetanol e combustivel, financiado em 90\% pelo Banco Nacional de Desenvolvimento Social - BNDES. Assim, classificou-se a frequência de interação com esse parceiro como média, sendo ele acessado em função de um projeto específico, a quantidade de tempo, curta, pois a mesma não se manteve ao longo desse período no projeto estudado. Um ponto interessante a esse respeito, que pôde ser observado, é a manutenção dessa parceria como uma forma de acessar novos conhecimentos para poder explorar novos produtos inovadores. 0 escopo do conteúdo compartilhado foi limitado, uma vez que restrito a esse novo projeto. Com a FAPESP, a empresa $A$ ainda possui alguns recursos de financiamento, porém em menor escala. Assim, os itens frequência de interação, quantidade de tempo e escopo do conteúdo foram classificados como médio, curto e limitado, respectivamente, muito embora o ator FAPESP tenha sido de extrema importância na viabilização da inovação criada pela empresa A, fornecendo os recursos iniciais para o desenvolvimento do projeto.

0 fundo de investimentos continua fazendo parte do quadro societário, assim como a empresa de consultoria. Com esses dois atores, a frequência de interação, quantidade de tempo, bem como o escopo de conteúdo foram, respectivamente, alta, longo e extenso, pois foram essas as parcerias desenvolvidas e mantidas no processo de fechamento da rede, caminhando de uma rede de exploração para uma rede de aplicação.

Segundo o modelo de inovação em rede proposto por Gobbo Junior e Olsson (2010), atores que partem de uma rede de transformação para uma de aplicação estabelecem parcerias, principalmente, com agentes financiadores e empreendedores interessados em comercializar as invenções. Dessa forma, verificou-se que a empresa A partiu de uma rede do tipo exploração e foi, ao longo do período analisado, estabelecendo parcerias que a auxiliassem na viabilização da inovação. Os atores responsáveis pela ligação entre um tipo de rede e outra, por parte da empresa A, foram: o fundo de investimento e a empresa de consultoria, respectivamente, corroborando o modelo de inovação proposto. Percebe-se, também, que o fundo de investimento atuou como um broker porque realizou a ligação entre a empresa A e a empresa de consultoria.

A Figura 2 ilustra o caminho percorrido pela empresa $A$, onde $A 1$ refere-se ao período da pré-ideia, A2 refere-se ao período da viabilização da ideia e A3 refere-se ao período da comercialização da ideia.

0 Quadro 2 ilustra as forças dos laços de relacionamento da empresa A com cada um de seus parceiros, nos períodos da pré-ideia, viabilização e comercialização da ideia.

Em relação à empresa $\mathrm{B}$, conclui-se que estava inserida numa rede do tipo aplicação, devidamente constituída, porém desejava se expandir, o que fez com que a diretora científica buscasse caminhos para inovar e, dessa forma, levar novos produtos ao mercado.

Com um projeto em mente, ela começou a buscar os meios para viabilizá-lo e o primeiro deles foi contratar um serviço de consultoria especializado para fazer um levantamento das possiveis plantas que tinham um tipo de agente químico que interessava à empresa. De posse dessa relação de plantas, ela estabeleceu uma parceria com o laboratório da UNESP de Botucatu para desenvolver parte de suas pesquisas. Isso aconteceu porque, nessa época, a empresa ainda não dispunha de todos os equipamentos necessários à viabilização das pesquisas iniciais exigidas pela nova empreitada.

Analisando a força dos laços com cada um desses parceiros durante o período da pré-ideia, verifica-se que a frequência de interação com o professor consultor foi baixa porque seu trabalho, num primeiro momento,

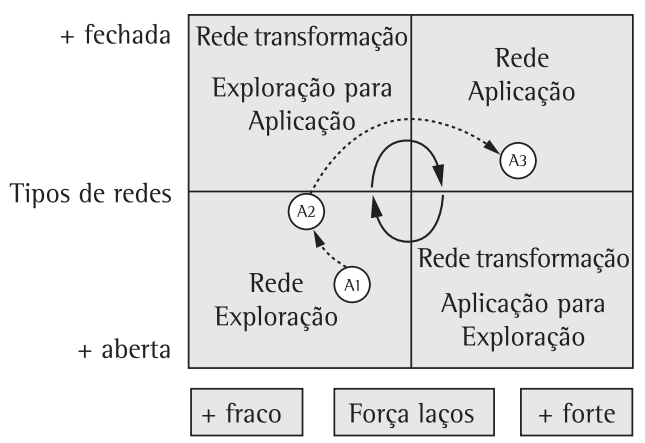

Figura 2. Caminho de inovação percorrido pela empresa $A$ ao longo da rede. 
consistiu numa ampla revisão bibliográfica, e para sua realização não foi preciso que ele permanecesse nas dependências da empresa, nem que algum representante dela permanecesse em seu escritório. Com o laboratório da UNESP de Botucatu a frequência de interação foi média porque, mesmo tendo algumas pesquisas sido terceirizadas junto a ele, supervisionadas diretamente pelo professor consultor contratado, essa etapa exigiu um acompanhamento por parte dos pesquisadores da empresa, que tiveram que se deslocar algumas vezes para acompanhar o seu andamento.

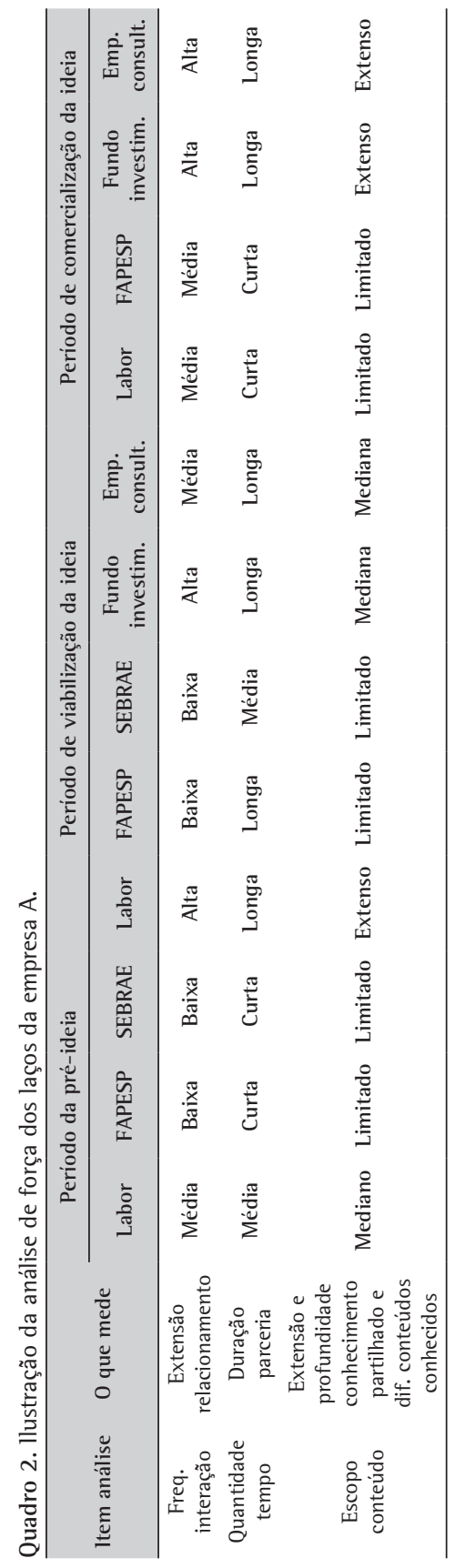

Quanto à quantidade de tempo, classifica-se como média com o professor consultor porque, apesar de ele permanecer em seu escritório desenvolvendo os estudos, foi mantido com ele um relacionamento ao longo de toda essa fase. Com o laboratório da UNESP de Botucatu a quantidade de tempo foi curta, pois foi acessado apenas no final do período.

No item análise do escopo do conteúdo, constatou-se que com o professor consultor ela foi mediana porque tratou-se de um trabalho muito específico e focado, muito embora os conhecimentos gerados por essa contratação tenham sido repassados à empresa. Com o laboratório da UNESP de Botucatu também foi mediano porque o conhecimento fluía de uma rede para outra, porém apenas para o trabalho que estavam desenvolvendo em comum.

No período da viabilização da ideia (2005 à 2007), as parcerias com o professor consultor e o laboratório da UNESP de Botucatu continuaram, porém houve a entrada de mais um parceiro, que foi a FAPESP, através do projeto PIPE. Graças a essa nova parceria, a empresa pôde continuar realizando suas pesquisas. 0 aporte de capital proporcionado foi decisivo para a contratação de pessoal qualificado. No início dessa segunda fase, a parceria com o laboratório da UNESP de Botucatu foi mantida porque a empresa B ainda precisou terceirizar algumas pesquisas, porém, com a aprovação da segunda fase do projeto PIPE junto à FAPESP, que aconteceu no final desse período, a empresa pôde adquirir os equipamentos necessários para completar o seu laboratório e passou a realizar todas as pesquisas.

Analisando as forças de laços com cada um desses parceiros durante essa fase, o item frequência de interação com o professor consultor foi média, porque ele ainda acompanhou o desenvolvimento dos testes, mas boa parte deles já estava sendo desenvolvida no laboratório da empresa, sob a coordenação e supervisão direta da diretoria científica e sua equipe de pesquisadores. Com o laboratório da UNESP de Botucatu, foi média, porque, após o aporte recebido da FAPESP, ele apenas finalizou as pesquisas que estavam em andamento. Embora como parceira a FAPESP tenha sido de importância crucial para o desenvolvimento das pesquisas necessárias à viabilização da inovação, com ela a interação foi baixa porque nesse tipo de parceria não se exige uma frequência de interação alta mas, sim, alguns relatórios em períodos pré-determinados pela concedente de capital.

No item quantidade de tempo, com o professor consultor foi longo, porque ele acompanhou, mesmo que não diretamente, todas as pesquisas realizadas durante essa etapa. Com o laboratório da UNESP de Botucatu, foi curto, porque a relação não foi mantida ao longo dessa fase, e com a FAPESP foi longo, mantendo-se durante essa fase. 
Quadro 3. llustração da análise de forças dos laços da empresa B.

\begin{tabular}{|c|c|c|c|c|c|c|c|c|}
\hline \multirow{2}{*}{ Item análise } & \multirow{2}{*}{0 que mede } & \multicolumn{2}{|c|}{ Período da pré-ideia } & \multicolumn{3}{|c|}{ Período da viabilização da ideia } & \multicolumn{2}{|c|}{$\begin{array}{c}\text { Período de comercialização } \\
\text { da ideia }\end{array}$} \\
\hline & & Prof. consultor & Lab. UNESP & $\begin{array}{l}\text { Prof. } \\
\text { consultor }\end{array}$ & $\begin{array}{l}\text { Lab. } \\
\text { UNESP }\end{array}$ & FAPESP & $\begin{array}{l}\text { Prof. } \\
\text { consultor }\end{array}$ & FAPESP \\
\hline $\begin{array}{c}\text { Freq. } \\
\text { interação }\end{array}$ & $\begin{array}{l}\text { Extensão } \\
\text { relacionam. }\end{array}$ & Baixa & Média & Média & Média & Baixa & Baixa & Baixa \\
\hline $\begin{array}{l}\text { Quantidade } \\
\text { tempo }\end{array}$ & $\begin{array}{l}\text { Duração } \\
\text { parceria }\end{array}$ & Média & Curta & Longa & Curta & Longa & longa & Média \\
\hline $\begin{array}{l}\text { Escopo } \\
\text { conteúdo }\end{array}$ & $\begin{array}{l}\text { Extensão e } \\
\text { profundidade } \\
\text { conhecimento } \\
\text { partilhado e } \\
\text { dif. conteúdos } \\
\text { conhecidos }\end{array}$ & Mediano & Mediano & Limitado & Mediano & Limitado & Limitado & Limitado \\
\hline
\end{tabular}

A análise do item escopo de conteúdo com o professor consultor constatou que foi extenso, embora as pesquisas estivessem sendo desenvolvidas no laboratório da empresa, porque durante essa fase o professor consultor teve acesso a todas elas. Percebeu-se que o conhecimento fluía entre as duas partes. Com o laboratório da UNESP de Botucatu foi mediano, porque os conhecimentos gerados no laboratório foram de extrema importância para a empresa continuar suas pesquisas. Quanto à FAPESP, foi limitado, porque o papel da parceira não foi transferir nem captar conhecimento mas, sim, fornecer os recursos financeiros necessários à execução e continuação das pesquisas.

No período da comercialização da idéia, as parcerias firmadas e mantidas foram: professor consultor e FAPESP. Analisando as forças de laços com cada um desses parceiros durante essa fase, o item frequência de interação com o professor consultor passou a ser baixa, pois foi um período de consolidação da inovação, não mais demandando conhecimentos produzidos por esse parceiro; com a FAPESP, ela continuou sendo baixa, realizada através de relatórios enviados conforme determinação.

No item quantidade de tempo com o professor consultor, ele continuou sendo longo porque, apesar do lançamento do produto no mercado, o professor continuou participando das pesquisas. Com a FAPESP, passou a ser médio porque, no ano de 2009 (um ano antes da finalização desse ciclo), a empresa entregou o último relatório de prestação de contas, encerrando-se, portanto, a parceria nesse projeto específico. Analisando-se o item escopo do conteúdo, constatou-se que com o professor consultor foi limitado, porque, nessa fase, o projeto foi concretizado. 0 mesmo ocorreu com a FAPESP, classificado como limitado o escopo de conteúdo pelo fato de esse tipo de parceria não se caracterizar pela transferência de conhecimentos.

Com base na análise apresentada, concluiu-se que a empresa B estava inserida numa rede do tipo

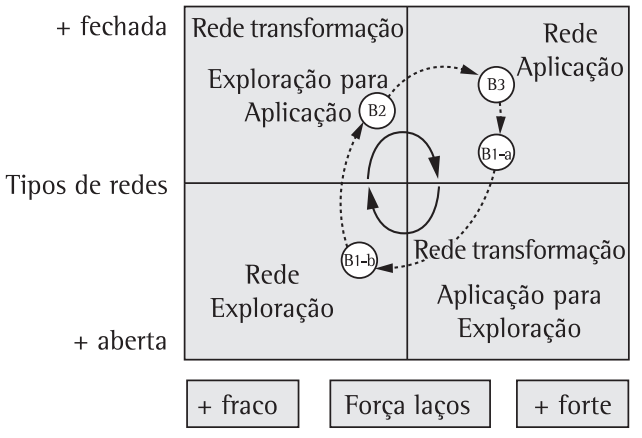

Figura 3. Caminho percorrido pela empreendedora da empresa $\mathrm{B}$ durante os três períodos analisados.

fechada e permaneceu nela ao longo de todos os períodos analisados, não alterando seu foco em nenhum momento. 0 que houve foi um movimento por parte da diretora científica que se moveu ao longo da rede, saindo das fronteiras da empresa (rede de aplicação) em busca de informações e recursos (rede de exploração). Constatou-se, também, que atuou como um broker no processo de inovação, porque estabeleceu as parcerias necessárias à viabilização da inovação.

Após a formação da equipe, acesso a novos conhecimentos e aquisição de recursos, a empreendedora novamente se moveu, voltando para sua rede de aplicação (empresa) para desenvolver as pesquisas e aperfeiçoar o conhecimento.

A Figura 3 ilustra o caminho que a empreendedora da empresa B percorreu ao longo da rede, durante os três períodos analisados. Assim, 1-a e 1-b referem-se à localização da empreendedora no período da pré-ideia; 2 refere-se à localização da empreendedora no período da viabilização da ideia; e 3 refere-se à localização da empreendedora no período de comercialização da ideia.

O Quadro 3 ilustra as forças dos laços de relacionamento da empresa $B$ com cada um de seus parceiros, nos períodos da pré-ideia, viabilização e comercialização da ideia. 


\section{Conclusões}

Segundo Gobbo Junior e Olsson (2010), as redes de transformação que partem de uma rede de exploração para uma rede de aplicação são um arranjo organizacional colaborativo, focado na ligação de redes complementares (exploração e aplicação) e na transferência de novos conhecimentos. Os atores típicos desse tipo de configuração de rede são: empreendedores, empresas, capitalistas de risco, bancos e escritórios de patentes. Por sua vez, as redes de transformação que partem de uma rede do tipo aplicação para exploração são um arranjo organizacional colaborativo focado em pesquisa, experimentação e complementação de conhecimentos e recursos. Os principais atores presentes nesse tipo de configuração de rede são: empreendedores, empresas, universidades, agências governamentais e serviços provedores de soluções tecnológicas.

Retomando as questões de pesquisa propostas, foi possível identificar, por meio da análise dos estudos de caso apresentados, os seguintes atores presentes nas redes de transformação que partem de uma rede do tipo exploração para aplicação: capitalista de risco e empreendedor, focados na ligação entre as redes e na complementação de conhecimentos e recursos. Quanto aos atores presentes nas redes de transformação que partiram de uma rede de aplicação para exploração foram identificados: empresa (fornecedora de conhecimentos/consultoria), um provedor de serviços de soluções tecnológicas e uma agência governamental, focados em pesquisas, experimentação e complementação de recursos.

Assim, pode-se afirmar que a rede de transformação identificada interliga as redes de exploração e aplicação e vice-versa, fornecendo os recursos financeiros e de conhecimento de que as empresas precisavam para viabilizar suas inovações. lsso corrobora as proposições apontadas por Gobbo Junior e Olsson (2010) em relação a como as redes de transformação fazem essa interligação e auxiliam a construção de evidências para a literatura de redes de inovação.

Também foi possivel constatar que as redes de transformação foram agentes aceleradores do processo de inovação desenvolvido pelas duas empresas, por meio da provisão dos recursos de que necessitavam para a sua viabilização.

Dessa forma, os objetivos propostos na presente pesquisa foram alcançados, uma vez que foi possível verificar como as redes de transformação interligam as redes de exploração e aplicação bem como identificar suas principais práticas: a) acesso aos recursos necessários; b) interesse por parte desse tipo de ator em comercializar novos produtos; c) ampliação da rede de contatos; e d) compartilhamento dos conhecimentos, bem como a identificação dos principais atores presentes nessa configuração de rede.
As principais limitações da presente pesquisa são: a) poucas evidências empíricas sobre os tipos de ator presentes nas redes de transformação; b) as métricas utilizadas na análise dos tipos de redes e forças de laços entre os parceiros.

As sugestões para pesquisas futuras são: busca de mais evidências empíricas no tocante à interligação das redes de transformação em outros segmentos de negócios e também em serviços; aperfeiçoamento das métricas utilizadas na análise dos tipos de redes e forças de laços e um estudo de inovações em redes no contexto da gestão do conhecimento.

\section{Referências}

AHUJA, G. Collaboration networks, structural holes, and innovation: a longitudinal study. Administrative Science Quarterly, v. 45, p. 425-455, 2000. http://dx.doi. org/10.2307/2667105

AMATO NETO, J. Redes entre organizações. São Paulo: Atlas, 2005.

BENNER, M. J.; TUSHMAN, M. L. Exploitation, exploration, and process management: The productivity dilemma revisited. Academy of Management Review, v. 28, p. 238256, 2003.

BERTHON, P.; HULBERT, J. M.; PITT, L. To serve or create? Strategic orientations toward costumers and innovation. California Management Review, v. 42, n. 1, 1999.

BRITTO, J. Redes de cooperação entre empresas. In: KUPFER, D. Economia industrial: fundamentos teóricos e práticos no Brasil. Rio de Janeiro: Campus, 2002.

BURT, R. S. Structural Holes: the social structures of competition. Cambridge: Harvard University Press, 1992.

CALIA, R.; GUERRINI, F.; MOURA, G. Innovation networks: from technological development to business model reconfiguration. Technovation, n. 27, v. 8, p. 426-432, 2007. http://dx.doi.org/10.1016/j. technovation.2006.08.003

CÂNDIDO, G. A.; ABREU, A. F. Os conceitos de redes e as relações interorganizacionais: um estudo exploratório. ln: ENCONTRO DA ENAMPAD, 24., 2000, Rio de Janeiro. Anais... Rio de Janeiro: ANPAD, 2000.

CHESBROUGH, H. Open Innovation: The New Imperative for Creating and Profiting from Tecnology. Cambridge: Harvard Business School Press, 2003.

CHESBROUGH, H. W.; GARMAN, A. R. Use Open Innovation to Cope in a Downturn. Harvard Business Review, 2009.

CHRISTENSEN, J. F.; OLESEN, M. H.; KJAER, J. S. The Industrial dynamics of Open Innovation - Evidence from the transformation of consumer electronics. Research Policy, v. 34, p. 1533-1549, 2005. http://dx.doi.org/10.1016/j. respol.2005.07.002

COLEMAN, J. S. Social Capital in the Creation of Human Capital. The American Journal of Sociology, v. 94, p. 95-120, 1988. http://dx.doi.org/10.1086/228943

COWAN, R.; JONARD, N.; ZIMMERMANN, J-B. Bilateral Collaboration and the Emergence of Networks. Management Science, v. 53, n. 7, p. 1051-1067, 2007. http://dx.doi.org/10.1287/mnsc.1060.0618

EASTERBY-SMITH, M.; CROSSAN, M.; NICOLINI, D. Organizational Learning: Debates past, present and future. Journal of Management Studies, v. 37, n. 6, 2000. http:// dx.doi.org/10.1111/1467-6486.00203

FREEMAN, C. The Economics of industrial Innovation. Cambridge: Mit Press, 1982. 
GILSING, V. A.; DUYSTERS, G. Understanding novelty creation in exploration networks: Structural and relational embeddedness jointly considered. Technovation, n. 28, p. 693-708, 2008. http://dx.doi.org/10.1016/j. technovation.2008.03.004

GOBBO JUNIOR, J. A.; VASCONCELlOS, M. A. Proposal of a framework for the analysis of the innovation process in networks. In: POMS ANNUAL CONFERENCE, 19., 2008, La Jolla, California. Proceedings... La Jolla, 2008.

GOBBO JUNIOR, J. A.; OLSSON, A. The transformation between exploration and exploitation applied to inventors of packaging innovations. Technovation, n. 30, p. 322-331, 2010. http://dx.doi.org/10.1016/j. technovation.2010.01.001

GRANOVETTER, M. S. The strength of weak ties. American Journal of Sociology, v. 78, n. 6, 1973. http://dx.doi. org/10.1086/225469

GRANT, R. M.; BADEN-FULLER, C. A knowledge accessing theory of strategic alliances. Journal of Management Studies, v. 41, p. 1, 2004. http://dx.doi.org/10.1111/ j.1467-6486.2004.00421.x

GUPTA, A. K.; SMITH, K. G.; SHALLEY, C. E. The interplay between exploration and exploitation. Academy of Management Journal, v. 49, p. 693-706, 2006. http:// dx.doi.org/10.5465/AMJ.2006.22083026

HARRISON, R. J.; CARROLL, G. R. The dynamics of cultural influence networks, Computational and mathematical organization theory, v. 8, n. 1, p. 5-30, 2002. http:// dx.doi.org/10.1023/A:1015142219808

HARRYSON, S. J.; DUDKOWSKI, R.; STERN, A. Transformation Networks in Innovation Alliances: The Development of Volvo C70. Journal of Management Studies, v. 45, n. 4, p. 745-773, 2008. http://dx.doi.org/10.1111/ j.1467-6486.2008.00768.x

HATCHUEL, A., WEIL, B. A new approach of innovative design: an introduction to C-K Theory. In: INTERNATIONAL CONFERENCE OF ENGINEERING DESIGN - ICED, 2003, Stockholm. Proceedings... Stockholm, 2003. p. 109-124.

KALLINIKOS, J. The social foundations of the bureaucratic order. Organization, v. 11, n. 1, 2004. http://dx.doi. org/10.1177/1350508404039657

KNOKE, D.; KUKLINSKI, J. Network analysis. Beverly Hills: Sage, 1982.

MARCH, J. G. Exploration and exploitation in organizational learning. Organization Science, v. 2, p. 71-87, 1991. http://dx.doi.org/10.1287/orsc.2.1.71

NOOTEBOOM, B. Towards a dynamic theory of transactions. Journal of Evolutionary Economics, v. 2, p. 281-299, 1992. http://dx.doi.org/10.1007/BF01200127
NO0TEBO0M, B. Inter-Firm Alliances: Analysis and Design. London: Routledge, 1999. http://dx.doi. org/10.4324/9780203265277

N00TEBO0M, B. Interfirm collaboration learning and network. London: Routledge, 2004.

PIRES, S. R. 1.; SACOMANO NETO, M. Características estruturais, relacionais e gerenciais na cadeia de suprimentos de um condomínio industrial na indústria automobilística. Produção, v. 20, n. 2, p. 172-185, 2010. http://dx.doi. org/10.1590/S0103-65132010005000032

PISANO, G. P. The research-and-development boundaries of the firm - an empirical - analysis. Administrative Science Quarterly, v. 35, n. 1, p. 153-176, 1990. http://dx.doi. org $/ 10.2307 / 2393554$

PISANO, G. P. The governance of innovation - vertical integration and collaborative arrangements in the biotechnology industry. Research Policy, v. 20, n. 3, p. 237-249, 1991. http://dx.doi.org/10.1016/00487333(91)90054-T

POWEL, W. W.; KOPUT, K. W.; SMITH-DOER, L. Interorganizational collaboration and the locuys of innovation: network of learning in biotechnology. Administrative Science Quarterly, v. 41, p. 116-145, 1996. http://dx.doi.org/10.2307/2393988

ROWLEY, T.; BERENS, D. E.; KRACKHARDT, D. Redundant governance structures: an analysis of structural and relacional embeddedness in the steel and semiconductor industries. Strategic Management Journal, v. 21, p. 369-386, 2000. http://dx.doi.org/10.1002/(SICl)10970266(200003)21:3\%3C369::AID-SMJ93\%3E3.0.CO;2-M

SAWHNEY, M. Managing business innovation: an advanced business analysis. Journal of Interactive Marketing, v. 16, p. 24-36, 2002.

SCHUMPETER, J. History of Economic Analysis. London: George Allen E Unwin, 1955.

SHENKAR, 0.; Ll, J. T. Knowledge search in international cooperative ventures. Organization Science, v. 10, n. 2, p. 134-143, 1999. http://dx.doi.org/10.1287/orsc.10.2.134

TEECE, D. J. Licensing and public-policy. Research Policy, v. 15, n. 6, p. 285-305, 1986. http://dx.doi.org/10.1016/00487333(86)90027-2

UZZI, B. Social structure and Competition in interfirm networks: the paradox of embeddedness. Administrative Science Quarterly, v. 42, p. 35-67, 1997. http://dx.doi. org/ $10.2307 / 2393808$

WASSERMAN, S.; FAUST, J. Social Network Analysis. Cambridge: Cambridge University Press, 1994.

YIN, R. K. Estudo de caso: Planejamento e métodos. 3. ed. Porto Alegre: Bookman, 2005.

\title{
The role of transformation networks in the process of innovation: case studies on the discovery and commercialization of innovation
}

\begin{abstract}
Innovation is widely recognized as important. In addition, in this context, innovation networks have gained importance in academic studies, since an organization alone, does not always have access to all necessary resources. Gobbo Junior and Olsson (2010) proposed a model of network innovation whereby the transformation networks would be the linking structures between exploration and exploitation networks. In this context, this paper presents two case studies of innovation networks, aiming to increase the understanding on transformation networks. The objective was to understand how they interconnect exploration and exploitation networks; the main actors present in this interface; and to evaluate whether these actors can act as agents, to accelerate the innovation process. It was possible to verify how the transformation networks interconnect exploration and exploitation, and identify the practices and their main actors.
\end{abstract}

\section{Keywords}

Innovation. Network theory. Exploration and exploitation networks. Models of innovation in networks. 


\section{Apêndice}

Entrevista semiestruturada aplicada às empresas

Empresa:

Respondente:

Cargo:

1. No início, quais foram as parcerias estabelecidas para viabilização da ideia?

2. Qual foi o critério de escolha desses parceiros?

3. Como era o relacionamento com cada um dos parceiros?

4. Como você classifica o grau de interação da empresa com os atores parceiros?

5. Como você classifica a duração dos relacionamentos com os parceiros?

6. Como você classifica o escopo do conhecimento compartilhado entre a empresa e seus parceiros?

7. Como você classifica os laços entre a empresa e seus parcerios?

8. No período de desenvolvimento do produto, as parcerias iniciais foram mantidas?

9. Houve a participação (entrada) de outros parceiros?

10. Qual foi o papel desempenhado por cada um deles?

11. Atualmente, quais parcerias a empresa possui?

12. Como é o relacionamento com cada um desses parcerios?

13. Qual foi o critério para a formação e a manutenção dessas parcerias?

14. 0 foco da empresa consiste em criar conhecimento ou aplicar conhecimento por meio da produção de bens e serviços?

15. Como a empresa acessou as informações necessárias à viabilização da inovação?

16. A WEB foi utilizada/acessada, em algum momento, na busca de informações para viabilização da inovação? De que forma? Representou alguma ajuda efetiva?

17. A empresa realiza gestão de inovação? Sim ( $\ldots$ _ $)$ Não ( $\ldots$ _ $)$ Como?

18. Como foi o caminho da inovação (descoberta e aplicação)?

19. Considerando "redes abertas" um tipo de rede cujo foco é a troca de recursos de informações e "rede fechada" uma rede cujo foco é a confiança entre seus membros (partilha de normas e trocas sociais), em qual desses dois tipos de rede a empresa está inserida? De que forma?

20. Sendo "ambidestridade" definida como a capacidade de a empresa estar alinhada de forma eficiente à gestão dos seus negócios atuais e, simultaneamente, explorar novos negócios, essa poderia ser denominada de ambidestra? Sim ( $\ldots$ _ $)$ Não ( $\ldots$ _ $)$ Por quê?

21. Sendo "rede de transformação" uma rede cujo objetivo é fazer a intersecção entre as redes de exploração e aplicação, auxiliando-as tanto na busca de conhecimentos novos quanto no fortalecimento de parcerias, a empresa utiliza esse tipo de rede?

22. Como são gerenciados os relacionamentos com esses atores? São relacionamentos formais ou informais? Qual a duração dos contratos com esses atores?

23. A empresa possui departamento de P\&D?

24. A empresa trabalha com pesquisadores externos? Eles são contratados ou bolsistas?

25. Quais os fatores mais importantes na busca e seleção de um ator? Quais são, em sua opinião, os fatores críticos para o sucesso nas parcerias em inovação?

26. A empresa investe em P\&D? Quanto? Existe um percentual fixo do faturamento destinado a essa finalidade? Por quê? Como esse caixa/fundo é administrado?

27. A empresa tem novos projetos em andamento? Quais? Em que estágio se encontram? Qual a previsão para seu lançamento?

28. Quanto foi investido em P\&D nos últimos 5 anos?

29. Quanto foi investido em inovação nos últimos 5 anos? 